\title{
The March 25, 1998 Antarctic Earthquake: Great earthquake caused by postglacial rebound
}

\author{
Seiji Tsuboi ${ }^{1 *}$, Masayuki Kikuchi² ${ }^{2}$ Yoshiko Yamanaka $^{2}$, and Masaki Kanao ${ }^{3}$ \\ ${ }^{1}$ Department of Geoscience, National Defense Academy, Yokosuka, Japan \\ ${ }^{2}$ Earthquake Research Institute, University of Tokyo, Tokyo, Japan \\ ${ }^{3}$ National Institute of Polar Research, Tokyo, Japan
}

(Received May 18, 1999; Revised December 10, 1999; Accepted December 10, 1999)

\begin{abstract}
A large $M_{w}=8.1$ earthquake occurred off southeast coast of Antarctica near the Balleny Island region on March 25, 1998. We inverted teleseismic body-wave records to determine the rupture pattern using an iterative deconvolution method. The source parameters obtained are: the centroid depth $=20 \mathrm{~km}$, (strike, dip, rake $)=(282$, $83,-1)$, the seismic moment $M_{0}=1.6 \times 10^{21} \mathrm{Nm}\left(M_{w}=8.1\right)$, the length $L=200 \mathrm{~km}$, and the average slip $D=4.4 \mathrm{~m}$. This earthquake occurred in the mid-plate but there has been no reports of such large earthquakes in this region. Furthermore, the source mechanism cannot be related to the plate motion inferred from the nearby transform faults. Therefore this earthquake is not a usual tectonic event. Here we show that the compressional axis of our source mechanism coincides with the horizontal crustal motion predicted by the Earth's response to present-day and past ice mass changes in Antarctica. Our result suggests that the 1998 Antarctica earthquake is caused by the postglacial rebound in the Antarctica.
\end{abstract}

\section{Introduction}

A large earthquake occurred off southeast coast of Antarctica on March 25, 1998. The hypocentral parameters given by the National Earthquake Information Service (NEIS) of USGS are: origin time $=03: 12: 24.7 \mathrm{UT}$, epicenter $=(62.876 \mathrm{~S}$, 149.712E), depth $=10 \mathrm{~km}$, magnitude $=8.0(\mathrm{Ms})$ and $M_{w}$ from the Harvard Centroid Moment Tensor (CMT) solution is 8.2. Figure 1 shows the ERI AutoCMT solution (Kawakatsu, 1995) of this earthquake and Harvard CMT solutions (Dziewonski et al., 1981) of the earthquakes that occurred around this region after 1977. The earthquake is located near transform faults of Australian-Antarctic ridge but this fault mechanism does not match with the strike of those transform faults (Fig. 1). In the present paper, we show that this fault mechanism is consistent with the crustal motion of the Antarctica derived from the Earth's response to present-day and past ice mass changes in Antarctica (James and Ivins, 1998). Our result suggests that this is the first earthquake ever detected caused by the postglacial rebound in the Antarctica.

\section{Mechanism}

We determine a sequence of subevents using the iterative deconvolution method (Kikuchi and Kanamori, 1991). We inverted 28 teleseismic broadband seismograms (vertical Pand SH-component) recorded by IRIS network. NEIS epicenter was then referred to as the initial break of the main

\footnotetext{
*Now at Faculty of Science, Yokohama City University, Yokohama, Japan.

Copy right(c) The Society of Geomagnetism and Earth, Planetary and Space Sciences (SGEPSS); The Seismological Society of Japan; The Volcanological Society of Japan;
} The Geodetic Society of Japan; The Japanese Society for Planetary Sciences. shock. The results of this inversion are summarized in Fig. 2. We obtained five subevents with almost the same strike-slip mechanisms that basically reveal two clusters. The first cluster consists of three subevents during the initial $50 \mathrm{sec}$. The rupture extends to $100 \mathrm{~km}$ west of the epicenter. The second cluster ruptures the area of $200 \mathrm{~km}$ west of the epicenter during 70 to $90 \mathrm{sec}$. Since the rupture mainly propagates from east to west, we may consider that the fault plane is the $\mathrm{P}$ wave nodal plane striking east-west. The main source parameters obtained are: the centroid depth $=20 \mathrm{~km}$; (strike, dip, rake $)=(282,83,-1)$; the seismic moment $M_{0}=1.6 \times 10^{21}$ $\mathrm{Nm}\left(M_{w}=8.1\right)$; the length $L=200 \mathrm{~km}$; assuming a width of $W=30 \mathrm{~km}$; the average slip $\mathrm{D}=M_{0} / \mu(L \times W)=4.4 \mathrm{~m}$. The centroid location nearly equals that of the Harvard CMT solution. The left-lateral strike-slip mechanism coincides with the aftershock distribution (Wiens et al., 1998) and consistent with the ERI AutoCMT solution (Fig. 1) which is obtained by using long-period body waves.

\section{Tectonic Implication}

The intraplate seismic activity is generally very low in the Antarctica (Kaminuma, 1994). There is no report of earthquakes in this century in the area where the present earthquake occurred. Although the centroid of this earthquake locates on the extension of nearby transform faults, the east-west strike of the fault plane of this earthquake does not coincide with the strike of the transform faults. Also the northeast-southwest compression in hypocenter area is opposite to the stress orientation of the earthquakes that occurred along the transform faults (Fig. 1). Thus it is not plausible to relate the fault mechanism of this earthquake to the plate motion of nearby transform faults. 


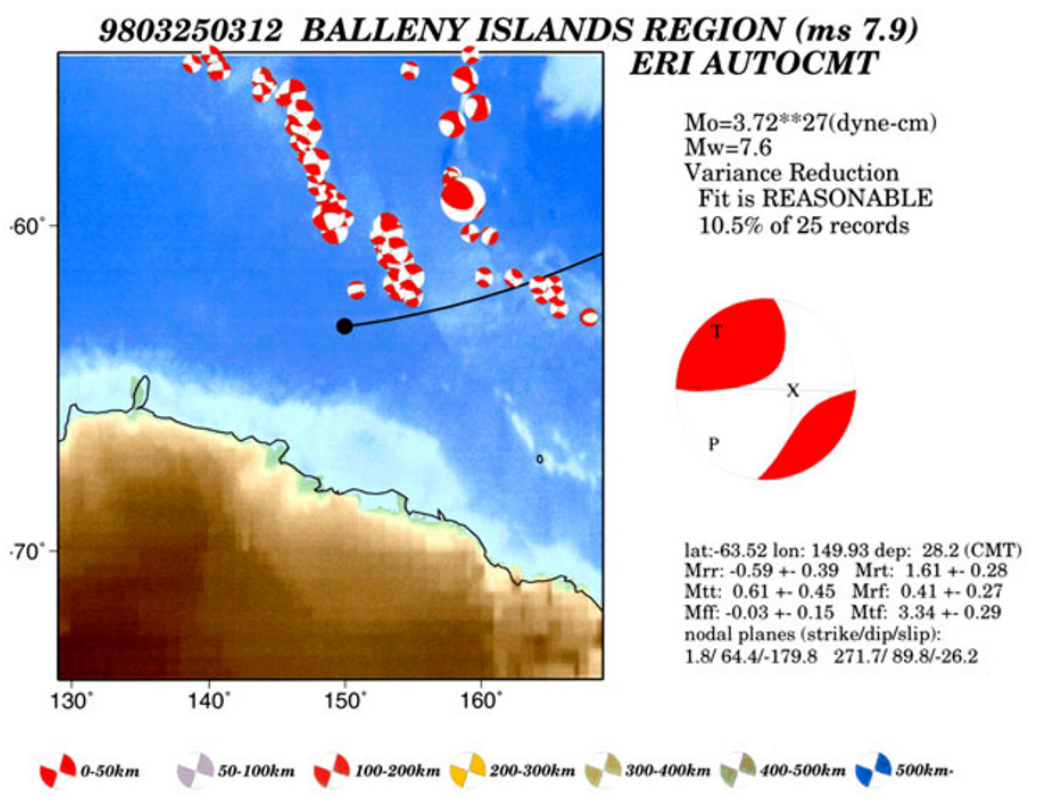

Fig. 1. Bathymetry of the region near the 1998 Balleny Islands earthquake and centroid moment tensor solution obtained by ERI AutoCMT analysis (Kawakatsu, 1995). The black dot in the map shows the centroid location. Harvard CMT mechanisms of earthquakes in this region are also shown. Focal mechanisms are drawn in lower hemisphere equal-area projection.

(a)
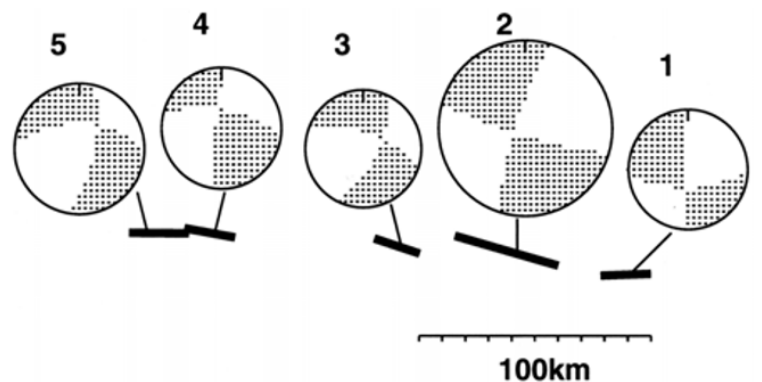

(b)

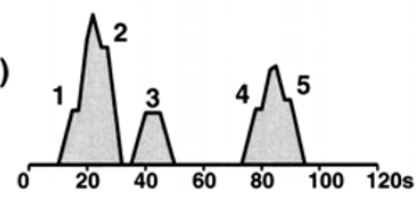

Fig. 2. Results of body wave inversion. (a) Spatial distribution of subevents and the mechanism diagram, the radius of which is proportional to the moment. (b) Moment-rate function.

\section{Postglacial Rebound}

Here we consider a possibility if postglacial rebound of the Antarctic ice sheet may cause this earthquake. It has been shown that a large scale surface lineament in northern Fennoscandia is a postglacial fault formed by $M_{w}=8$ earthquake which occurred shortly after the local deglaciation 9000 years ago (Arvidsson, 1996; Johnston, 1996). Hunt and Malin (1998) suggested that similar postglacial earthquake had occurred in northern Canada. Thus removal of the ice sheet at the end of the last glaciation may cause non-isostatic compressive stresses and trigger large earthquakes. The postglacial rebound in the Antarctica is difficult to measure since most of the continent is still covered by ice. Only very limited observation is available for the crustal motion around Antarctica (Kaminuma and Akamatsu, 1992). Currently,

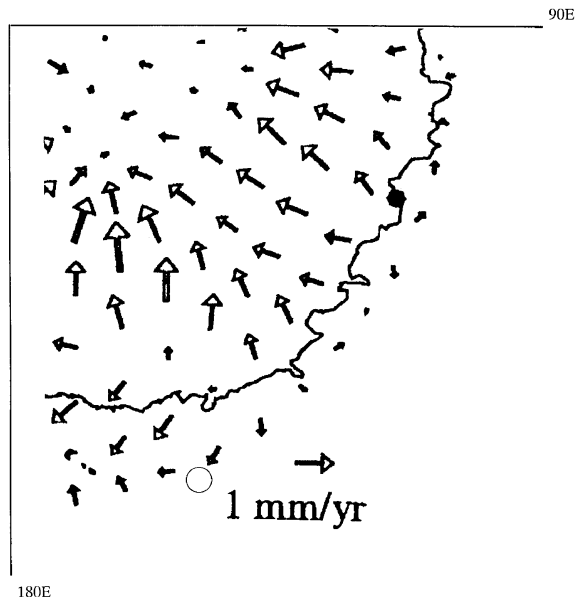

Fig. 3. Predicted crustal motion in south-east Antarctica taken from figure 13(b) of James and Ivins (1998). Open circle denotes the location of the epicenter of this earthquake.

model calculation is performed to predict crustal response caused by deglaciation of the Antarctic ice sheet (James and Ivins, 1995, 1998; Wahr et al., 1995). James and Ivins (1998) computed both vertical and horizontal crustal responses assuming the past and present-day ice mass changes in Antarctica (Denton and Hughes, 1981; Denton et al., 1991). They incorporated a visco-elastic response as well as an elastic response of the spherically symmetric Earth model. In figure 13 of their results, they assumed that the deglaciation begins at 12000 years and ends at 5000 years to calculate crustal motion. Their result shows that the horizontal crustal motion around the hypocenter area of this earthquake is in the northeast direction with velocity about $\sim 1 \mathrm{~mm} /$ yr. Fig. 3 shows a southeast part of their figure. This direction of the 
horizontal crustal motion coincides with the compressional axis of the fault mechanism of this earthquake. We may assume at the plate boundary that either the displacement of the horizontal crustal motion is zero or there exists a slight ridge push. Then, 5000 years of horizontal crustal motion with constant rate of $1 \mathrm{~mm} / \mathrm{yr}$ may result in deformation of about $5 \mathrm{~m}$ around the hypocenter area. This is comparable with the dislocation obtained for this earthquake.

One may argue that the horizontal displacement might be rather complex around the hypocenter area in Fig. 3. However, for a weak zone such as a pre-existing fault, it is the component of crustal movement projected onto this zone that drives the fault motion. Recent analysis (Kikuchi and Kanamori, 1995) of large earthquakes reveals that the great earthquakes occur not only at plate boundaries but also within plates. Therefore it is not surprising that there exists some fault structure in this hypocenter region. There seems to be a general tendency that the horizontal movement is northeast to east direction, which can accumulate a driving force along the locked fault.

Since the deformation occurred over past 5000 years, it is consistent with the fact that there is no report of earthquake in this century around the present earthquake. It is likely that another $M \approx 8$ earthquake had occurred 5000 years ago when the deglaciation was over and the rate of crustal movement could be large. After that event, the fault had been locked again and the strain had accumulated along the fault.

Based on these arguments, we believe that the postglacial rebound is a plausible candidate to explain the cause of this earthquake.

\section{Discussion}

Stein et al. (1989) has shown that maximum stresses induced by glacial loading occur within a few hundred kilometers of the load, since bending of the crust causes stresses at the edge of the ice sheet. Since the epicenter of this earthquake was more than $500 \mathrm{~km}$ away from the edge of the ice sheet, one may consider that it is too far from the location where the postglacial unloading exerts sufficient stresses to cause a large earthquake. However this argument assumes that the great earthquake should occur where the stress level becomes large enough to initiate rupture without pre-existing fault, which is unlikely as we discussed before.

Since the great earthquakes occur at plate boundaries or along the pre-existing fault, it is not necessary that strain rate or stress rate should be maximum at the hypocenter region of this earthquake. Figure 3 predicts the north-east crustal movement with $1 \mathrm{~mm} / \mathrm{yr}$ at the hypocenter region. If we assume that the fault had been locked for the past 5000 years, this $1 \mathrm{~mm} / \mathrm{yr}$ displacement would accumulate as strain on the fault. We assume that thinning of the ice sheet that locates just south of the epicenter caused the vertical uplift of the crust, which is shown in figure 13(a) of James and Ivins (1998); this accompanied the horizontal compression around the epicenter area. Compressive stress may accumulate in this manner, which eventually led to this large earthquake.

James and Ivins (1998) discusses several scenarios for the deglaciation history. Figure 11 in their paper shows that the horizontal crustal motion for a different scenario gives opposite direction for horizontal crustal motion around this source region. In that scenario, the deglaciation begins at 9000 years ago and ends at 4000 years ago. If the predicted crustal motion around this fault area is opposite to the P-axis direction of this earthquake, then, the accumulated strain along the fault should cause an earthquake which has a completely different fault solution. The fact that different model gives different horizontal crustal motion might suggest that the fault mechanism of this earthquake can be used to constrain the deglaciation history of the Antarctic ice sheet, which has a significant contribution on past climate change.

We do not have a geophysical observation that confirms the pre-existence of the fault around the hypocenter area. However, if we perform geophysical field observation, such as multichannel reflection survey, we may be able to find a geological record which indicates that the fault had caused earthquakes repeatedly in the past. To confirm our hypothesis that this earthquake was caused by the post glacial rebound, such an observation is needed.

\section{Summary}

We have obtained a fault mechanism of March 25, 1998 Antarctic earthquake by using iterative deconvolution technique. The result shows that the fault plane of this event is left-lateral strike slip with east-west strike. This fault mechanism cannot be explained by the plate motion of the nearby transform faults. We have shown that horizontal crustal motion predicted by the postglacial rebound of the Antarctica coincides with not only the direction but also the average dislocation calculated from our result. Our result suggests that this earthquake is caused by the postglacial rebound of the Antarctica and may be used to constrain the deglaciation history in the Antarctica.

Acknowledgments. We would like to express our gratitude to two anonymous reviewers for their constructive comments regarding this work.

\section{References}

Arvidsson, R., Fennoscandian earthquakes: Whole crustal rupturing related to postglacial rebound, Science, 274, 744-746, 1996.

Denton, G. H. and T. J. Hughes, The Last Great Ice Sheets, 484 pp., John Wiley \& sons, New York, 1981.

Denton, G. H., M. L. Prentice, and L. H. Burckle, Cainozoic history of the Antarctic ice sheet, in Geology of Antarctica, edited by R. J. Tingey, pp. 365-433, Oxford Univ. Press, New York, 1991.

Dziewonski, A. M., T. -A. Chou, and J. H. Woodhouse, Determination of earthquake source parameters from waveform data for studies of global and regional seismicity, J. Geophys. Res., 86, 2825-2852, 1981

Hunt, A. G. and P. E. Malin, Possible triggering of Heinrich events by iceload-induced earthquakes, Nature, 393, 155-158, 1998.

James, T. S. and E. R. Ivins, Present-day Antarctic ice mass changes and crustal motion, Geophys. Res. Lett., 22, 973-976, 1995.

James, T. S. and E. R. Ivins, Predictions of Antarctic crustal motions driven by present-day ice sheet evolution and by isostatic memory of the Last Glacial Maximum, J. Geophys. Res., 103, 4993-5017, 1998.

Johnston, A. C., A wave in the Earth, Science, 274, 735, 1996.

Kaminuma, K., Seismic activity in and around the Antarctic continent, Terra Antartica, 1, 423-426. 1994.

Kaminuma, K. and J. Akamatsu, Intermittent micro-seismic activity in the vicinity of Syowa station, east Antarctica, in Recent Progress in Antarctic Earth Science, edited by Y. Yoshida et al., pp. 493-497, Terrapub, 1992

Kawakatsu, H., Automated near-realtime CMT inversion, Geophys. Res. Lett., 22, 2569-2572, 1995.

Kikuchi, M. and H. Kanamori, Inversion of complex body waves-III, Bull. Seism. Soc. Am., 81, 2335-2350, 1991.

Kikuchi, M. and H. Kanamori, The Shikotan earthquake of October 4, 1994 
Lithospheric earthquake, Geophys. Res. Lett., 22, 1025-1028, 1995.

Stein, S., S. Cloetingh, N. H. Sleep, and R. Wortel, Passive margin earthquakes, stresses, and rheology, in Earthquakes at North-Atlantic passive margins, edited by S. Gregersen and P. W. Basham, pp. 231-259, Kluwer Academic Publishers, the Netherlands, 1989.

Wahr, J. H., H. DaZhong, and A. Trupin, Predictions of vertical uplift caused by changing polar ice volumes on a viscoelastic earth, Geophys. Res. Lett., 22, 977-980, 1995.
Wiens, D., M. E. Wysession, and L. Lawver, Recent oceanic intraplate earthquake in Balleny Sea was largest ever detected, Eos Trans. $A G U$, 79(30), 353-354, 1998.

S. Tsuboi (e-mail: tsuboi@yokohama-cu.ac.jp), M. Kikuchi (e-mail: kikuchi@eri.u-tokyo.ac.jp), Y. Yamanaka (e-mail: sanchu@, eri.u-tokyo.ac.jp), and M. Kanao (e-mail: kanao@nipr.ac.jp) 